\title{
Analytical Solution of Interface Effect on the Strength of Combined Model Composed of Different Geologic Bodies
}

\author{
Zeng-hui Zhao,, ${ }^{1,2}$ Wei-ming Wang, ${ }^{3}$ Li-hua Wang, ${ }^{3}$ and Ji-xing Yan $^{3}$ \\ ${ }^{1}$ State Key Laboratory of Mining Disaster Prevention and Control Cofounded by Shandong Province and the Ministry of \\ Science and Technology, Shandong University of Science and Technology, Qingdao 266590, China \\ ${ }^{2}$ College of Mining and Safety Engineering, Shandong University of Science and Technology, Qingdao 266590, China \\ ${ }^{3}$ College of Civil Engineering and Architecture, Shandong University of Science and Technology, Qingdao 266590, China
}

Correspondence should be addressed to Zeng-hui Zhao; qzzh2004@163.com

Received 26 April 2014; Revised 24 June 2014; Accepted 25 June 2014; Published 5 August 2014

Academic Editor: Gisele Mophou

Copyright (c) 2014 Zeng-hui Zhao et al. This is an open access article distributed under the Creative Commons Attribution License, which permits unrestricted use, distribution, and reproduction in any medium, provided the original work is properly cited.

\begin{abstract}
According to the special combined structure of surrounding rock in western mining area of China, a micromechanical model with variable parameters containing contact interface was proposed firstly. Then, the derived stresses in coal and rock near the interface were analyzed on the basis of the harmonized strain relation, and the analytical solutions with respect to stress states near the interface were drawn up. The triaxial compressive strength of coal and rock was further determined in case the contact interface was in the horizontal position. Moreover, effects of stiffness ratio, interface angle, and stress level on the strength of two bodies near the contact area were expounded in detail. Results indicate that additional stresses which have significant effect on the strength of combined model are derived due to the adhesive effect of contact interface and lithological differences between geologic bodies located on both sides. The interface effect on the strength of combined body is most associated with the stiffness, interface angle, and the stress level. These conclusions are also basically valid for three-body model and even for the multibody model and lay important theory foundation to guide the stability study of soft strata composed of different geologic bodies.
\end{abstract}

\section{Introduction}

Roadway in western mining area of China is generally arranged in the relatively hard coal seam due to the unstable weakly cemented soft rock strata, so a unique combined structure of surrounding rock composed of coal and rock is formed. However, some mining disasters such as fall and weak shock in roof and terrible floor heave are frequently occurring. Actually, these disasters are closely related to the overall mechanical behavior of special structure of surrounding structure whose stability is determined by the comprehensive interaction between different geologic bodies. Mechanical behavior between different geologic bodies exhibits discontinuity and inhomogeneity due to their lithological differences and the contact effect which makes the combined body show abnormal mechanical behavior. Therefore, it has important engineering significance for predicting the stability of roadway to make clearly the interface effect on rock strength.
Currently, studies at home and abroad mainly focus on the joint surface which plays a key role in mechanical behavior and stability of rock mass. Among them, special attention was paid to the shear strength of the joint surface since the sliding failure theory of two-dimensional weak plane presented by [1] in 1960. At present, dozens of wellknown shear constitutive models to predict the criteria of shear strength for interfaces have been proposed [2-4]. However, these models are two-dimensional and cannot reflect the real contact state of interface. Given this, in [5, 6], a statistical mathematical model describing the relation between the effective shear angle of interface element and the corresponding contact area through a large number of direct shear tests for joint surface was studied, and furthermore a three-dimensional shear model was established. On this basis, a modified peak strength model was put forward in [7] which can reflect the dilatancy effect considering the relationship between the shear dilatancy angle at peak and the characteristic of three-dimensional morphology. In addition, 
some constitutive models for the mechanical behavior of interface in normal and tangential directions were developed in $[8,9]$, and the degradation of interface asperities was discussed in [10]. The above conclusions have achieved good results for the study of mechanical properties of joint in rock, but they are only suitable for a single rock medium. Actually, the lithological difference between geologic bodies on both sides of the contact surface has an important effect on the failure mode of combined body which has been proved by indoor test [11]. Many scholars have studied the contact behavior between engineering body and geologic body. In [12, 13], the contact behavior between rock and concrete was systematically analyzed from experimental and theoretical aspects. Bimaterials and bibodies models for combined body composed of engineering body and geologic body were established in [14-16] considering the different contact characteristics. In $[17,18]$, the effect of contact behavior on the cracking of dam was analyzed. Up to now, some scholars have carried out studies on the mechanical behavior of combined model in underground engineering. For example, the stability of two body model composed of roof and coal was studied in [19]. In [20, 21], the effect of contact angle on the integral strength of coal-rock combination model was analyzed. In [22], a double shear friction test for sandstone-coal composite sample was carried out by biaxial loading system, and the frictional sliding behavior of coal during impact buckling was analyzed. Based on a series of compressive tests, it is found that the integral strength of coal-rock combination model is between the strength of strong rock and weak coal, and the mechanical behavior of combined model is closely related to the monomer property as well as the combination style in $[23,24]$.

The above findings have studied in detail the integral mechanical behavior of combined model and the contact characteristics which show important significance for understanding the influence of interface effect on combined model. However, the results of interface effect on different mediums are only based on the macroscopic failure of combined model from test aspect, and quantitative theory is insufficient to measure the influence degree. Therefore, based on coal-rock combination model as main research object, we proposed a micromechanical model with variable parameters containing contact interface in this study. Then, the analytical analysis of interface effect on stress states of different geologic bodies on both sides was carried out in order to quantify the influence degree of contact interface on different rock mediums near contact area. All the drawn conclusions laid the theoretical foundation for further studying the stability of surrounding rock from the angle of combined model.

\section{Mechanical Model of Interface Effect}

From geological exploration data, mining area of western China is mainly located in soft rock strata as shown in Figure 1. Roof and floor with respect to the occurrence condition of coal seam are mainly weakly cemented soft rock as carbonaceous mudstone, fine sandstone, mudstone, silty

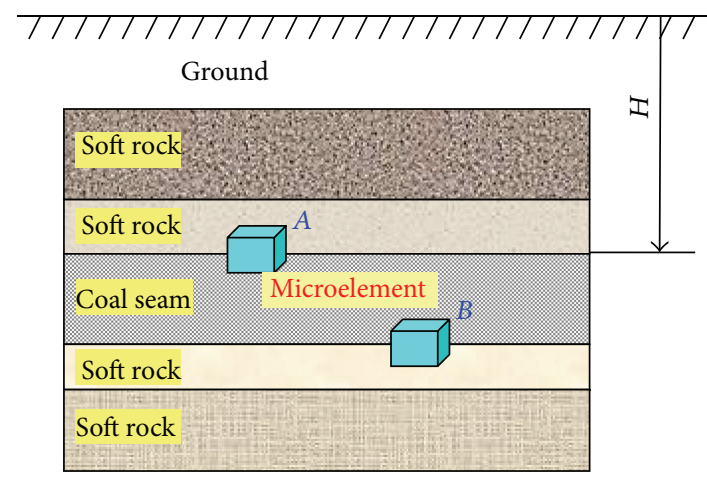

FIGURE 1: Occurrence condition of coal seam in weakly cemented soft rock strata.

mudstone, and so on [25]. If roadway is excavated in coal seam, the stability of surrounding rock is explicitly determined by the combined structure of soft rock and coal. For convenience, the thickness of contact interface is neglected here. A microelement marked as A which contained soft rock, coal, and interface was selected in order to analyze the interface effect. Apparently, the model has the special characteristic of varying material parameters. Without loss of generality, the contact angle is set an arbitrary direction. The enlarged model is shown in Figure 2(a).

Lithological difference between soft rock and coal will surely result in mutual restraint stress at the contact interface in order to keep the strain compatibility under loading. For inclined interface, both restraint normal stress and shear stress will be derived. For convenient analysis, the contact interface was firstly transformed to a horizontal direction through three-dimensional coordinate transformation and stresses also performed the corresponding transformation as shown in Figures 2(b) and 2(c).

With the help of the formula of rotated axes, namely, $\sigma_{i j}^{\prime}=\sigma_{i j} \cdot n_{i i} \cdot n_{j j}$, the calculation results of stresses after transformation can be expressed as

$$
\begin{aligned}
& {\left[\begin{array}{l}
\sigma_{x} \\
\sigma_{y} \\
\sigma_{z}
\end{array}\right]=\left[\begin{array}{lll}
l_{1}^{2} & m_{1}^{2} & n_{1}^{2} \\
l_{2}^{2} & m_{2}^{2} & n_{2}^{2} \\
l_{3}^{2} & m_{3}^{2} & n_{3}^{2}
\end{array}\right]\left[\begin{array}{l}
\sigma_{1} \\
\sigma_{2} \\
\sigma_{3}
\end{array}\right],} \\
& {\left[\begin{array}{l}
\tau_{x y} \\
\tau_{y z} \\
\tau_{z x}
\end{array}\right]=\left[\begin{array}{lll}
l_{1} l_{2} & m_{1} m_{2} & n_{1} n_{2} \\
l_{2} l_{3} & m_{2} m_{3} & n_{2} n_{3} \\
l_{3} l_{1} & m_{3} m_{1} & n_{3} n_{1}
\end{array}\right]\left[\begin{array}{l}
\sigma_{1} \\
\sigma_{2} \\
\sigma_{3}
\end{array}\right],}
\end{aligned}
$$

where $l_{i}, m_{i}$, and $n_{i}$ represent the direction cosine between the new coordinate axis and the old, respectively. The corresponding relationship is

$$
\begin{array}{cccc} 
& 1 & 2 & 3 \\
x & l_{1} & m_{1} & n_{1} \\
y & l_{2} & m_{2} & n_{2} \\
z & l_{3} & m_{3} & n_{3} .
\end{array}
$$




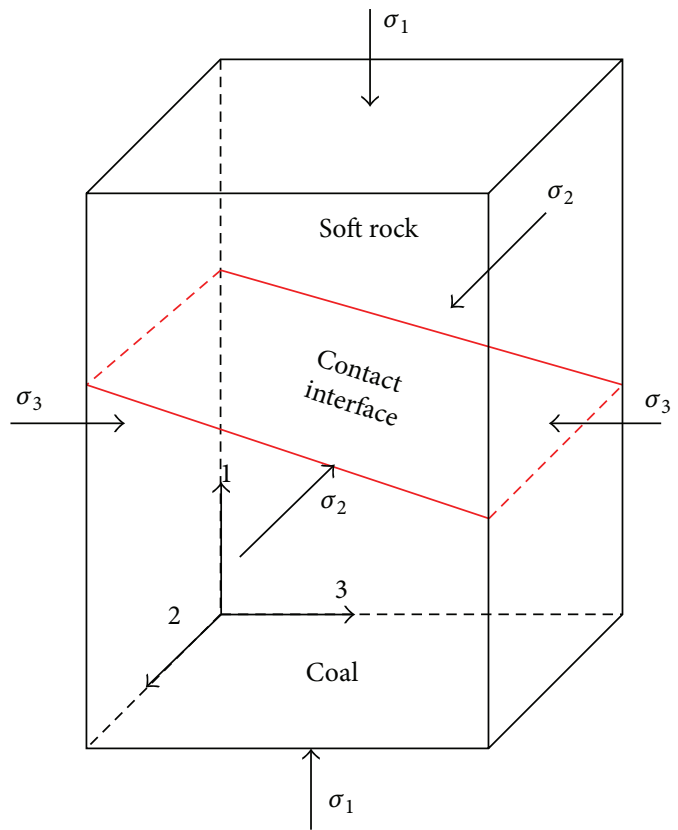

(a) Micromodel

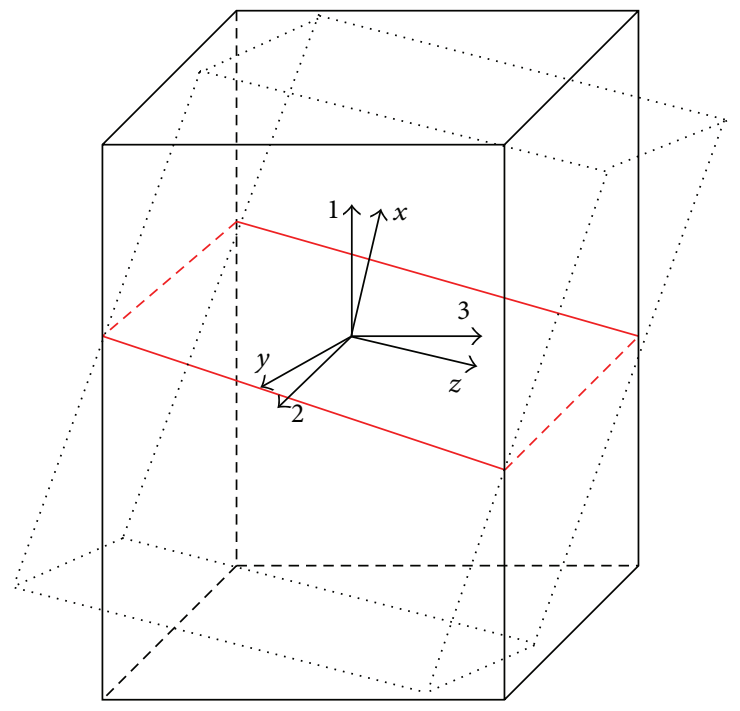

(b) Coordinate transformation

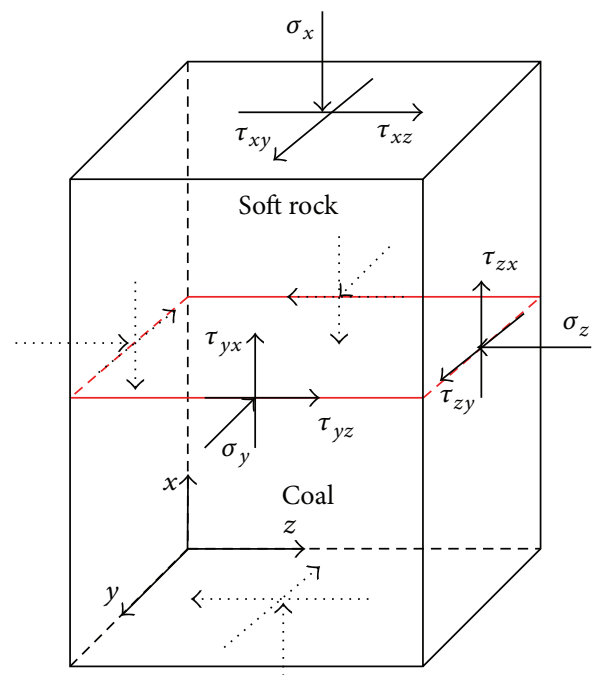

(c) Micromodel after transformation

FIGURE 2: Mechanical model of microelement.

\section{Stress State Analysis of Coal and Rock Near Interface Area}

3.1. Decomposition of Interfacial Mechanical Model. The contact interface between coal and rock is considered to have bonding strength. Let elastic modulus of soft rock and coal body be $E_{r}, E_{m}$, and let Poisson's ratio be $v_{r}, v_{m}$, respectively. The difference of elastic constants will lead to different deformation in the two geological bodies under the same loading condition. Nevertheless, the same deformation must be produced near the interface due to the bonding condition, so it is inevitable for tensile and compressive stress as well as shear stress to be derived in the two different geological bodies near the interface area. This will result in a sharp discontinuity of stress and continuity of displacement in coal and rock body around the interface.

For the analysis of the derived stress, the mechanical model of microelement after coordinate transformation was divided into the following two parts by employing the superposition principal: one is only under the action of normal stress as shown in Figure 3(a) and the other is under shear stress presented in Figure 3(b).

\subsection{Derived Stresses in Different Geologic Bodies under Normal} Stress. Let be $E_{r}>E_{m}, v_{r}<v_{m}, \alpha=E_{r} / E_{m}$, and $\beta=v_{r} / v_{m}$. Compressive stress is specified as positive later on. Only normal stresses will be derived in the plane of $x o y, y o z$, and $z o x$, 


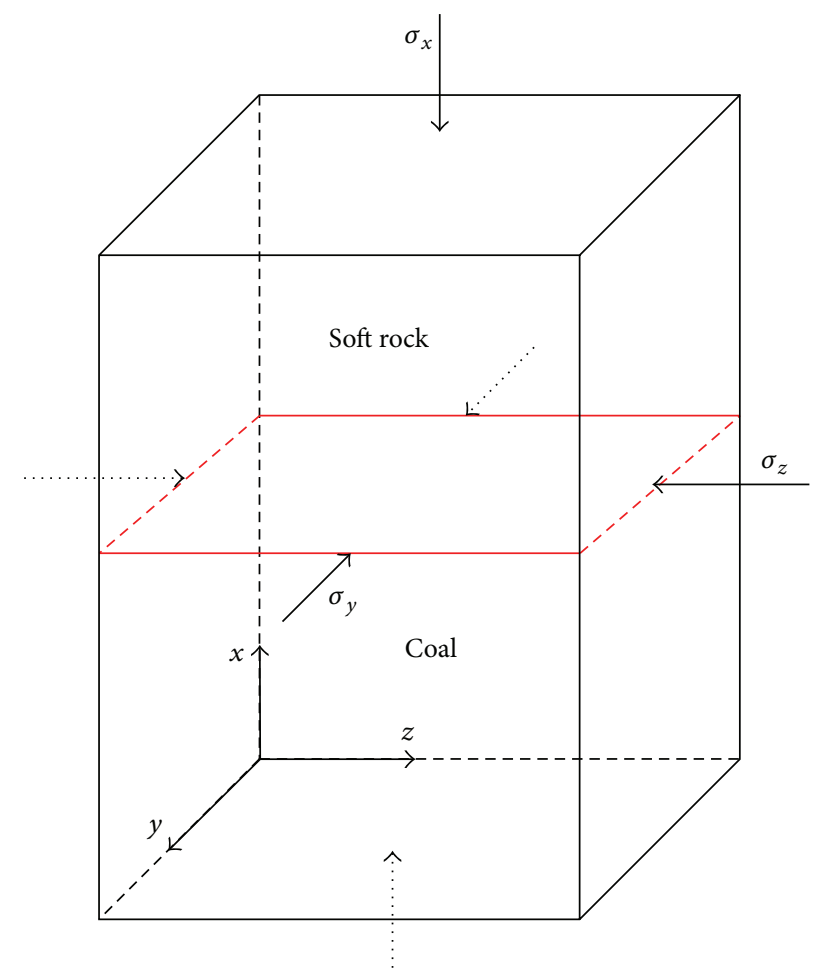

(a) Action of normal stress

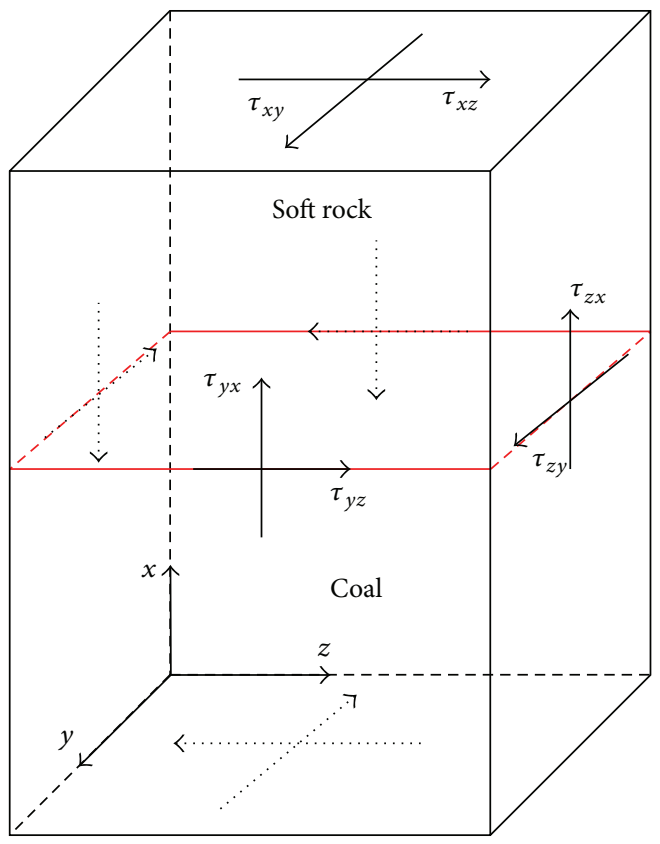

(b) Action of shear stress

FIGURE 3: Stress decomposition diagram for analysis model.

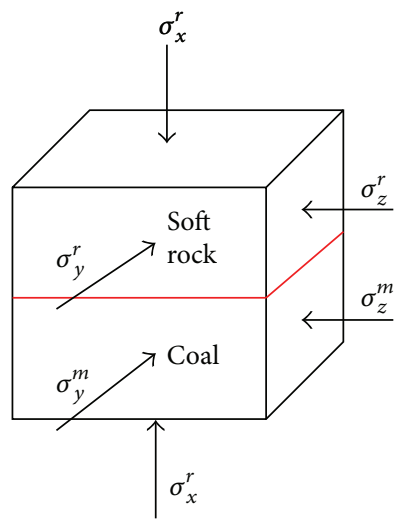

(a) Total normal stress

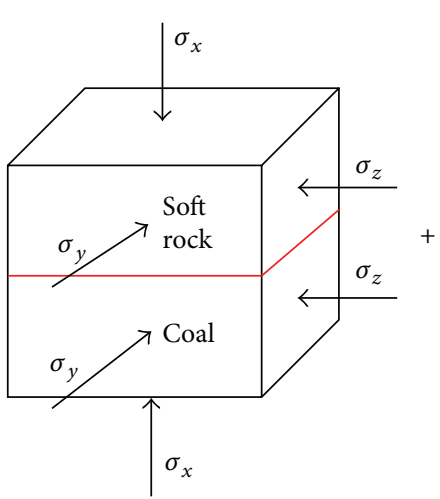

(b) Original normal stress

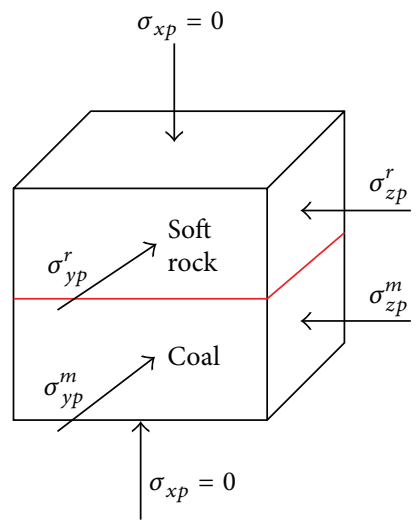

(c) Derived normal stress

FIgURE 4: The normal stress distribution of micromodel.

respectively, under the action of the original normal stresses. Figure 4(a) presented the distribution of total normal stress acting on the micromodel which is composed of the origin stress and derived stress as shown in Figures 4(b) and 4(c), respectively. According to the superposition principal, the relationships between them are

$$
\begin{aligned}
& \sigma_{x}^{r}=\sigma_{x}, \\
& \sigma_{x}^{m}=\sigma_{x}, \\
& \sigma_{y}^{r}=\sigma_{y}+\sigma_{y p}^{r},
\end{aligned}
$$

$$
\begin{gathered}
\sigma_{y}^{m}=\sigma_{y}+\sigma_{y p}^{m}, \\
\sigma_{z}^{r}=\sigma_{z}+\sigma_{z p}^{r}, \\
\sigma_{z}^{m}=\sigma_{z}+\sigma_{z p}^{m},
\end{gathered}
$$

where superscript $r$ and $m$, respectively, stand for soft rock and coal body and subscript $p$ denotes the derived stress.

The harmonious relationship of longitudinal strain in the transverse plane $(y o z)$ near the interface area was 


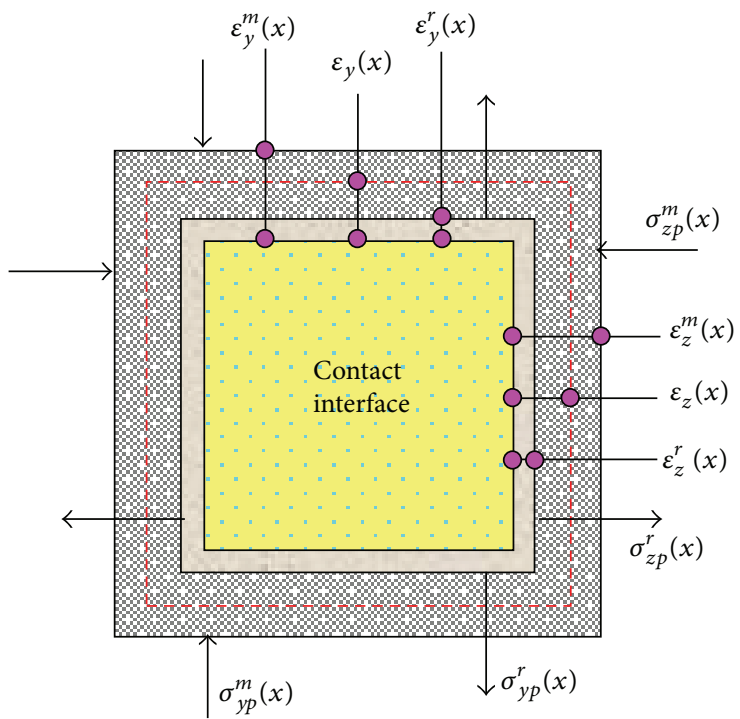

(a) Action of $\sigma_{x}$

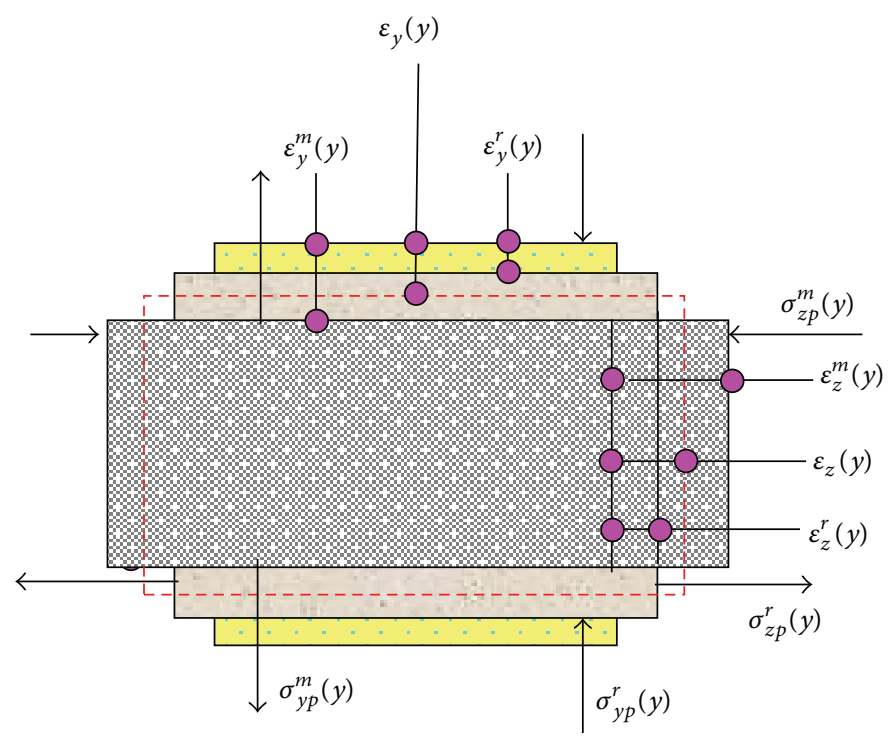

(b) Action of $\sigma_{y}$

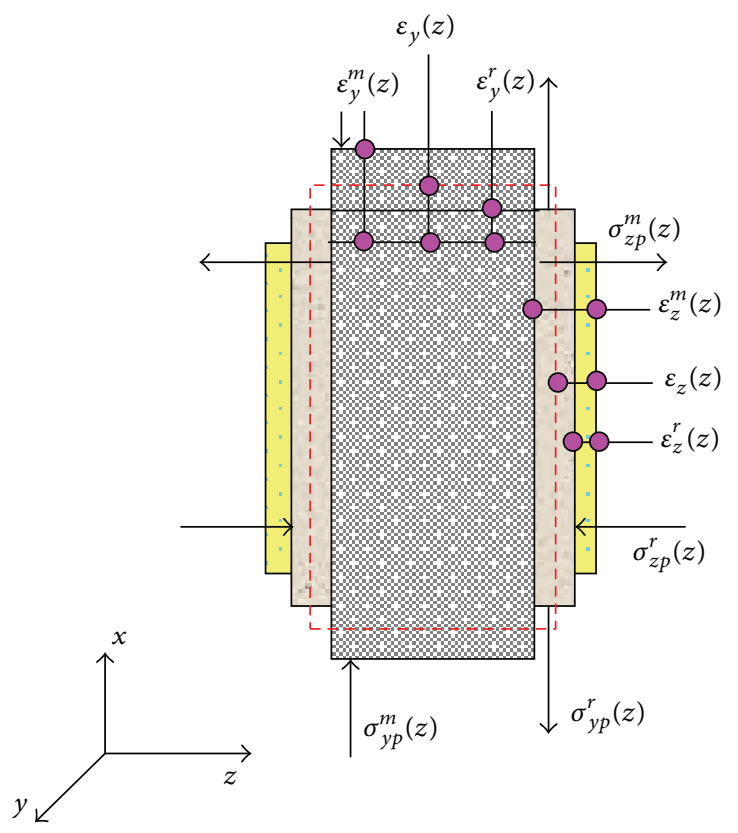

(c) Action of $\sigma_{z}$

FIgURE 5: The transverse strain relationship near contact interface under normal stress.

demonstrated in Figure 5 when the normal stress in three directions was applied, respectively.

As shown in Figure 5(a), the soft rock and coal will transversely expand in $y$ and $z$ directions, respectively, under the action of $\sigma_{x}$. Thus, tensile strain will be produced in the two geologic bodies in each direction. Among them, the strain in the coal body is, respectively, written as $\varepsilon_{y}^{m}(x)$ and $\varepsilon_{z}^{m}(x)$, and the strain in soft rock is denoted by $\varepsilon_{y}^{r}(x)$ and $\varepsilon_{z}^{r}(x)$, respectively, where $x$ stands for the action direction of normal stress. Because of the assumed relations of $E_{r}>$ $E_{m}$ and $v_{r}<v_{m}$, comparison results of the transverse strain in the two geologic bodies should be $\varepsilon_{y}^{r}(x)<\varepsilon_{y}^{m}(x)$ and $\varepsilon_{z}^{r}(x)<\varepsilon_{z}^{m}(x)$, respectively. However, these transverse stains must satisfy the harmonious relation according to the bonding interface. Thus, the final results of transverse strains in the two geologic bodies are denoted by $\varepsilon_{y}(x)$ and $\varepsilon_{z}(x)$, respectively. For this reason, compressive stresses will be derived in coal body which are demonstrated by $\sigma_{y p}^{m}(x)$ and $\sigma_{z p}^{m}(x)$ in each direction. On the contrary, tensile stresses will be induced in soft rock which are accordingly written as $\sigma_{y p}^{r}(x)$ and $\sigma_{z p}^{r}(x)$, respectively. Their relations should be $\sigma_{y p}^{m}(x)=\sigma_{y p}^{r}(x)$ and $\sigma_{z p}^{m}(x)=\sigma_{z p}^{r}(x)$ based on 
the equilibrium relationship. For convenience, the derived stresses in $y$ and $z$ direction are unified written as $\sigma_{y p}(x)$ and $\sigma_{z p}(x)$, respectively.

Similarly, when $\sigma_{y}$ is applied to the model individually as shown in Figure 5(b), derived compressive stress and tensile stress in $z$ and $y$ directions will be produced in coal body which are denoted as $\sigma_{z p}^{m}(y)$ and $\sigma_{y p}^{m}(y)$, respectively. In contrast, derived compressive stress $\sigma_{y p}^{r p}(y)$ and tensile stress $\sigma_{z p}^{r}(y)$ will be applied to soft rock in $y$ and $z$ directions. In addition, they should meet the following relation: $\sigma_{y p}^{m}(y)=$ $\sigma_{y p}^{r}(y)$ and $\sigma_{z p}^{m}(y)=\sigma_{z p}^{r}(y)$. As before, the derived stresses in each direction are written as $\sigma_{y p}(y)$ and $\sigma_{z p}(y)$, respectively. Besides, the derived stresses in the two geologic bodies in $y$ and $z$ directions are denoted by $\sigma_{y p}(z)$ and $\sigma_{z p}(z)$, respectively, under the action of $\sigma_{z}$ as demonstrated in Figure 5(c).

From the above analysis, when one of the normal stresses is applied to the model, derived normal stresses will be induced in other two directions in the two geologic bodies near contact area. These derived stresses will distinctly affect the integral strength and failure mode of coal-rock combination model. As shown in Figure 5, the longitudinal strains should satisfy

$$
\begin{aligned}
& \varepsilon_{y}^{r}(x)=\varepsilon_{y}^{m}(x)=\varepsilon_{y}(x), \\
& \varepsilon_{z}^{r}(x)=\varepsilon_{z}^{m}(x)=\varepsilon_{z}(x), \\
& \varepsilon_{y}^{r}(y)=\varepsilon_{y}^{m}(y)=\varepsilon_{y}(y), \\
& \varepsilon_{z}^{r}(y)=\varepsilon_{z}^{m}(y)=\varepsilon_{z}(y), \\
& \varepsilon_{y}^{r}(z)=\varepsilon_{y}^{m}(z)=\varepsilon_{y}(z), \\
& \varepsilon_{z}^{r}(z)=\varepsilon_{z}^{m}(z)=\varepsilon_{z}(z) .
\end{aligned}
$$

By substituting the generalized Hooke's law into (4), the derived normal stresses can be calculated as

$$
\begin{gathered}
\sigma_{y p}(x)=a_{y x} \sigma_{x}, \\
\sigma_{z p}(x)=a_{z x} \sigma_{x}, \\
\sigma_{y p}(y)=a_{y y} \sigma_{y}, \\
\sigma_{z p}(y)=a_{z y} \sigma_{y}, \\
\sigma_{y p}(z)=a_{y z} \sigma_{z}, \\
\sigma_{z p}(z)=a_{z z} \sigma_{z},
\end{gathered}
$$

where

$$
\begin{aligned}
& a_{y x}=\frac{v_{m}(\alpha-\beta)}{(\alpha+1)-v_{m}(\alpha+\beta)}, \\
& a_{z x}=\frac{v_{m}(\alpha-\beta)}{(\alpha+1)-v_{m}(\alpha+\beta)}, \\
& a_{y y}=\frac{\alpha^{2}-1-v_{m}^{2}\left(\alpha^{2}-\beta^{2}\right)}{(\alpha+1)^{2}-v_{m}^{2}(\alpha+\beta)^{2}},
\end{aligned}
$$

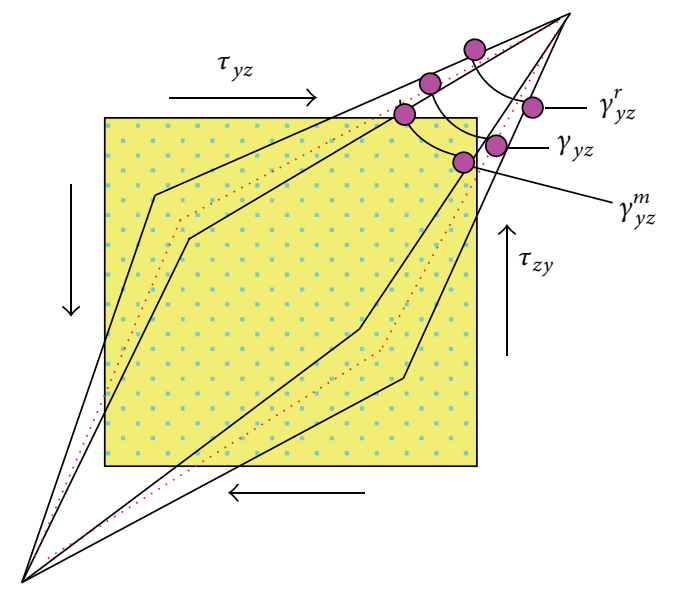

FIGURE 6: The relationship of transverse shear strain near contact interface.

$$
\begin{aligned}
& a_{z y}=\frac{2 v_{m} \alpha(1-\beta)}{(\alpha+1)^{2}-v_{m}^{2}(\alpha+\beta)^{2}}, \\
& a_{y z}=\frac{2 v_{m} \alpha(1-\beta)}{(\alpha+1)^{2}-v_{m}^{2}(\alpha+\beta)^{2}}, \\
& a_{z z}=\frac{\alpha^{2}-1-v_{m}^{2}\left(\alpha^{2}-\beta^{2}\right)}{(\alpha+1)^{2}-v_{m}^{2}(\alpha+\beta)^{2}} .
\end{aligned}
$$

Obviously, the coefficients satisfy $a_{y x}=a_{z x}, a_{y y}=a_{z z}$, and $a_{z y}=a_{y z}$. The analytical expression of normal stresses in the two geologic bodies is deduced as follows by substituting (5) into (3):

$$
\begin{aligned}
& \sigma_{x}^{r}=\sigma_{x}^{m}=\sigma_{x}, \\
& \sigma_{y}^{r}=-a_{y x} \sigma_{x}+\left(1+a_{y y}\right) \sigma_{y}-a_{y z} \sigma_{z}, \\
& \sigma_{z}^{r}=-a_{z x} \sigma_{x}-a_{z y} \sigma_{y}+\left(1+a_{z z}\right) \sigma_{z}, \\
& \sigma_{y}^{m}=a_{y x} \sigma_{x}+\left(1-a_{y y}\right) \sigma_{y}+a_{y z} \sigma_{z}, \\
& \sigma_{z}^{m}=a_{z x} \sigma_{x}+a_{z y} \sigma_{y}+\left(1-a_{z z}\right) \sigma_{z} .
\end{aligned}
$$

3.3. Derived Stresses in Different Geologic Bodies under Shear Stress. When the shear stresses are applied to the model individually as shown in Figure 3(b), no normal stress will be derived by neglecting the coupling effect between longitudinal strain and shear strain. On this condition, only shear stress which is related to the transverse deformation will induce derived shear stress. Therefore, only $\tau_{y z}$ and $\tau_{z y}$ in Figure 3(b) affect the interface effect. Figure 6 demonstrates the harmonious relationship of shear strain in transverse plane under the action of shear stress.

Let $E_{r}>E_{m}$ and $v_{r}<v_{m}$, finding $G_{r}>G_{m}$ where $G$ denotes the shear modulus. Thus, the transverse shear strain in coal body and soft rock should satisfy $\gamma_{y z}^{m}>\gamma_{y z}^{r}$. However, the two should keep harmonious relationship due 


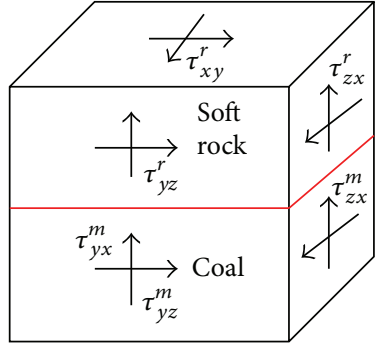

(a) Total shear stress

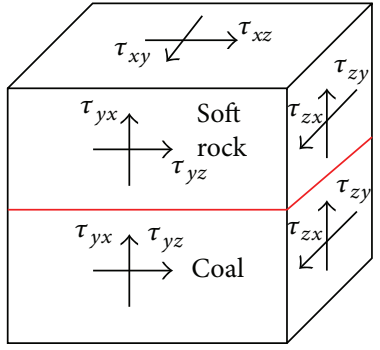

(b) Original shear stress

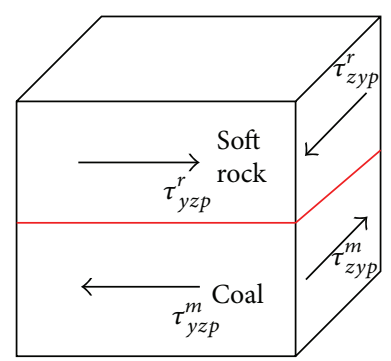

(c) Derived shear stress

FIGURE 7: Distribution of shear stress near contact interface.

to the transverse constraint, so unified final transverse shear strain is written as $\gamma_{y z}$. And this means that derived shear stresses which are denoted by $\tau_{y z p}^{r}$ and $\tau_{y z p}^{m}$ will be induced in the two geologic bodies under the action of original shear stress $\tau_{y z}$ and $\tau_{z y}$ as shown in Figure 7.

Thus, the shear stresses on the model near contact area should be determined as

$$
\begin{gathered}
\tau_{x y}^{r}=\tau_{x y}^{m}=\tau_{x y}, \\
\tau_{z x}^{r}=\tau_{z x}^{m}=\tau_{z x}, \\
\tau_{y z}^{r}=\tau_{y z}+\tau_{y z p}^{r}, \\
\tau_{y z}^{m}=\tau_{y z}-\tau_{y z p}^{m} .
\end{gathered}
$$

Substituting (8) into the relation $\gamma_{y z}^{m}=\gamma_{y z}^{r}=\gamma_{y z}$ and $\tau_{y z p}^{r}=\tau_{y z p}^{m}$, then

$$
\tau_{y z p}^{r}=\tau_{y z p}^{m}=\frac{(\alpha-1)+v_{m}(\alpha-\beta)}{(\alpha+1)+v_{m}(\alpha+\beta)} .
$$

The shear stresses near contact area can be further determined by substituting (9) into (8); that is

$$
\begin{aligned}
& \tau_{x y}^{r}=\tau_{x y}^{m}=\tau_{x y}, \\
& \tau_{z x}^{r}=\tau_{z x}^{m}=\tau_{z x}, \\
& \tau_{y z}^{r}=\frac{2 \alpha\left(1+v_{m}\right)}{(\alpha+1)+v_{m}(\alpha+\beta)} \tau_{y z}=b_{r} \tau_{y z}, \\
& \tau_{y z}^{m}=\frac{2\left(1+\beta v_{m}\right)}{(\alpha+1)+v_{m}(\alpha+\beta)} \tau_{y z}=b_{m} \tau_{y z} .
\end{aligned}
$$

3.4. Analytical Model of Stress States in the Two Geologic Bodies Near Contact Area. Stress state of soft rock near contact area is confirmed as follows by substituting (7) and (10) into (1): consider

$$
\begin{aligned}
& {\left[\begin{array}{l}
\sigma_{x}^{r} \\
\sigma_{y}^{r} \\
\sigma_{z}^{r}
\end{array}\right]=\left[\begin{array}{ccc}
l_{1}^{2} & m_{1}^{2} & n_{1}^{2} \\
A_{21} & A_{22} & A_{23} \\
A_{31} & A_{32} & A_{33}
\end{array}\right]\left[\begin{array}{l}
\sigma_{1} \\
\sigma_{2} \\
\sigma_{3}
\end{array}\right],} \\
& {\left[\begin{array}{c}
\tau_{x y}^{r} \\
\tau_{y z}^{r} \\
\tau_{z x}^{r}
\end{array}\right]=\left[\begin{array}{ccc}
l_{1} l_{2} & m_{1} m_{2} & n_{1} n_{2} \\
b_{r} l_{2} l_{3} & b_{r} m_{2} m_{3} & b_{r} n_{2} n_{3} \\
l_{3} l_{1} & m_{3} m_{1} & n_{3} n_{1}
\end{array}\right]\left[\begin{array}{l}
\sigma_{1} \\
\sigma_{2} \\
\sigma_{3}
\end{array}\right],}
\end{aligned}
$$

where

$$
\begin{aligned}
& A_{21}=-a_{y x} l_{1}^{2}+\left(1+a_{y y}\right) l_{2}^{2}-a_{y z} l_{3}^{2}, \\
& A_{22}=-a_{y x} m_{1}^{2}+\left(1+a_{y y}\right) m_{2}^{2}-a_{y z} m_{3}^{2}, \\
& A_{23}=-a_{y x} n_{1}^{2}+\left(1+a_{y y}\right) n_{2}^{2}-a_{y z} n_{3}^{2}, \\
& A_{31}=-a_{z x} l_{1}^{2}-a_{z y} l_{2}^{2}+\left(1+a_{z z}\right) l_{3}^{2}, \\
& A_{32}=-a_{z x} m_{1}^{2}-a_{z y} m_{2}^{2}+\left(1+a_{z z}\right) m_{3}^{2}, \\
& A_{33}=-a_{z x} n_{1}^{2}-a_{z y} n_{2}^{2}+\left(1+a_{z z}\right) n_{3}^{2} .
\end{aligned}
$$

Similarly, we can obtain the stress state of coal body near contact area as

$$
\begin{aligned}
& {\left[\begin{array}{l}
\sigma_{x}^{m} \\
\sigma_{y}^{m} \\
\sigma_{z}^{m}
\end{array}\right]=\left[\begin{array}{ccc}
l_{1}^{2} & m_{1}^{2} & n_{1}^{2} \\
B_{21} & B_{22} & B_{23} \\
B_{31} & B_{32} & B_{33}
\end{array}\right]\left[\begin{array}{l}
\sigma_{1} \\
\sigma_{2} \\
\sigma_{3}
\end{array}\right],} \\
& {\left[\begin{array}{c}
\tau_{x y}^{m} \\
\tau_{y z}^{m} \\
\tau_{z x}^{m}
\end{array}\right]=\left[\begin{array}{ccc}
l_{1} l_{2} & m_{1} m_{2} & n_{1} n_{2} \\
b_{m} l_{2} l_{3} & b_{m} m_{2} m_{3} & b_{m} n_{2} n_{3} \\
l_{3} l_{1} & m_{3} m_{1} & n_{3} n_{1}
\end{array}\right]\left[\begin{array}{l}
\sigma_{1} \\
\sigma_{2} \\
\sigma_{3}
\end{array}\right],}
\end{aligned}
$$

where

$$
\begin{aligned}
& B_{21}=a_{y x} l_{1}^{2}+\left(1-a_{y y}\right) l_{2}^{2}+a_{y z} l_{3}^{2}, \\
& B_{22}=a_{y x} m_{1}^{2}+\left(1-a_{y y}\right) m_{2}^{2}+a_{y z} m_{3}^{2}, \\
& B_{23}=a_{y x} n_{1}^{2}+\left(1-a_{y y}\right) n_{2}^{2}+a_{y z} n_{3}^{2}, \\
& B_{31}=a_{z x} l_{1}^{2}+a_{z y} l_{2}^{2}+\left(1-a_{z z}\right) l_{3}^{2}, \\
& B_{32}=a_{z x} m_{1}^{2}+a_{z y} m_{2}^{2}+\left(1-a_{z z}\right) m_{3}^{2}, \\
& B_{33}=a_{z x} n_{1}^{2}+a_{z y} n_{2}^{2}+\left(1-a_{z z}\right) n_{3}^{2} .
\end{aligned}
$$

From (11) and (13), the stress states in two geologic bodies are changed due to the bonding interface, and some of the stress components are not continuous because of the differences of deformation parameter. Let $\alpha=\beta=1 ; a_{y x}$, $a_{y y}$, and $a_{z y}$ are equal to 0 , respectively, and no derived stress is induced in the model. 


\section{Influence of Interface Effect on the Model Strength}

4.1. Strength of the Two Geologic Bodies Near Contact Area under Triaxial Compression. For convenient discussion, let inclined angle of contact interface be 0 ; find $l_{1}=m_{2}=n_{3}=1$. Substituting the relation into (11), the stress state in soft rock is determined as

$$
\begin{aligned}
\sigma_{x}^{r} & =\sigma_{1}, \\
\sigma_{y}^{r} & =-a_{y x} \sigma_{1}+\left(1+a_{y y}\right) \sigma_{2}-a_{y z} \sigma_{3}, \\
\sigma_{z}^{r} & =-a_{z x} \sigma_{1}-a_{z y} \sigma_{2}+\left(1+a_{z z}\right) \sigma_{3}, \\
\tau_{x y}^{r} & =\tau_{y z}^{r}=\tau_{z x}^{r}=0 .
\end{aligned}
$$

And the stress state in coal body can be expressed as

$$
\begin{aligned}
\sigma_{x}^{m} & =\sigma_{1}, \\
\sigma_{y}^{m} & =a_{y x} \sigma_{1}+\left(1-a_{y y}\right) \sigma_{2}+a_{y z} \sigma_{3}, \\
\sigma_{z}^{m} & =a_{z x} \sigma_{1}+a_{z y} \sigma_{2}+\left(1-a_{z z}\right) \sigma_{3}, \\
\tau_{x y}^{m} & =\tau_{y z}^{m}=\tau_{z x}^{m}=0 .
\end{aligned}
$$

It is evident the micromodel is changed as the principal element for each geologic body under this condition. Let the yielding conditions of coal and rock meet Mohr-Coulomb yielding criterion, respectively; namely,

$$
\begin{gathered}
\sigma_{1}^{r}=\xi_{r} \sigma_{3}+\eta_{r}, \\
\sigma_{1}^{m}=\xi_{m} \sigma_{3}+\eta_{m},
\end{gathered}
$$

where $\xi_{i}=\left(1+\sin \varphi_{i}\right) /\left(1-\sin \varphi_{i}\right)$ and $\eta_{i}=2 c_{i} /\left(1-\sin \varphi_{i}\right)$ $(i=r, m) . \varphi_{i}$ and $c_{i}$, respectively, represent the friction angle and cohesion.

Geologic bodies at the far interface will be less affected by interface effect, and their strength under triaxial compression can be established according to (17) because there is no variation in their stress states. However, the stresses of geologic bodies near the contact area will be evidently changed due to the interface effect, so strength will be dramatically affected. If $\sigma_{y}^{r}>\sigma_{z}^{r}$, then $\sigma_{z}^{r}$ is the third principal stress $\sigma_{3}$, and the compression strength of soft rock near contact area is determined as

$$
\sigma_{1}^{r}=\frac{\xi_{r}\left[-a_{z y} \sigma_{2}+\left(1+a_{z z}\right) \sigma_{3}\right]}{1+\xi_{r} a_{z x}}+\frac{\eta_{r}}{1+\xi_{r} a_{z x}} .
$$

On the contrary, if $\sigma_{y}^{r}<\sigma_{z}^{r}$, the third principal stress $\sigma_{3}$ is related to $\sigma_{y}^{r}$, and the compression strength of soft rock near contact area is established as

$$
\sigma_{1}^{r}=\frac{\xi_{r}\left[\left(1+a_{y y}\right) \sigma_{2}-a_{y z} \sigma_{3}\right]}{1+\xi_{r} a_{y x}}+\frac{\eta_{r}}{1+\xi_{r} a_{y x}} .
$$

Similarly, if $\sigma_{y}^{m}>\sigma_{z}^{m}$, the compression strength of coal body near contact area is written as

$$
\sigma_{1}^{m}=\frac{\xi_{m}\left[a_{z y} \sigma_{2}+\left(1-a_{z z}\right) \sigma_{3}\right]}{1-\xi_{m} a_{z x}}+\frac{\eta_{m}}{1-\xi_{m} a_{z x}} .
$$

And if $\sigma_{y}^{m}<\sigma_{z}^{m}$, the compression strength is changed as

$$
\sigma_{1}^{m}=\frac{\xi_{m}\left\lfloor\left(1-a_{y y}\right) \sigma_{2}+a_{y z} \sigma_{3}\right\rfloor}{1-\xi_{m} a_{y x}}+\frac{\eta_{m}}{1-\xi_{m} a_{y x}} .
$$

In fact, if the order of principal stress in combined model satisfies $\sigma_{1}>\sigma_{2} \geq \sigma_{3}$, the stresses in the two geologic bodies will constantly meet $\sigma_{y}^{r}>\sigma_{z}^{r}$ and $\sigma_{y}^{m}>\sigma_{z}^{m}$ due to the coefficient relationship of $a_{y y}=a_{z z}$ and $a_{z y}=a_{y z}$. Thus, the compressive strengths of soft rock and coal can be directly calculated using (18) and (20), respectively.

4.2. Effect of Rock Stiffness on the Strengths of Two Geologic Bodies. The following basic parameters are set: $c_{m}=1 \mathrm{MPa}$, $\varphi_{m}=30^{\circ}, E_{m}=1 \mathrm{GPa}, c_{r}=2 \mathrm{MPa}, \varphi_{r}=40^{\circ}$. Let the stiffness ratio between soft rock and coal be $\alpha$. Effect of rock stiffness on the strength of micro model is analyzed below by gradually increasing the rock modulus and keeping the coal modulus constantly.

Figure 8 demonstrates the strength variation of two geologic bodies near contact area with rock stiffness when $\sigma_{2}$ and $\sigma_{3}$ are set to $2 \mathrm{MPa}$ and $3 \mathrm{MPa}$, respectively. In the results, $\sigma_{1}^{m}$ and $\sigma_{1}^{r}$, respectively, stand for the strength of coal and soft rock which are not affected by contact interface. The corresponding affected strengths are distinguished by superscript $m c$ and $r c$ which are denoted by $\sigma_{1}^{m c}$ and $\sigma_{1}^{r c}$. Thus, the variation of strengths is calculated as $\Delta \sigma_{1}^{m}=\sigma_{1}^{m c}-\sigma_{1}^{m}$ and $\Delta \sigma_{1}^{r}=\sigma_{1}^{r}-\sigma_{1}^{r c}$. From Figure 8(a), the strength of coal body (weak body) under triaxial compression is greatly improved due to the interface effect, and the variation $\Delta \sigma_{1}^{m}$ presents increasing trend with the rising of stiffness ratio $\alpha$. When $\alpha>2$, the strength of coal body $\sigma_{1}^{m c}$ will exceed that of soft rock $\sigma_{1}^{r c}$ near the contact area due to the action of derived stresses. On the contrary, strength of soft rock is decreased with the increasing of $\alpha$. When $\alpha>3, \sigma_{1}^{r c}$ tends to be steady and is approximately equal to the strength of coal body $\sigma_{1}^{m c}$.

The uniaxial compression strengths shown in Figure 8 (b) exhibit the same changing trend with the results in Figure 8(a). When $\alpha<1.5$, the strength of soft rock near contact area is higher than that of coal body, but the results are just opposite when $\alpha>2.5$. Actually, if $E_{r}>E_{m}$ and $\mu_{r}<\mu_{m}$, the transverse tensile strain of soft rock near contact area will be less than that of coal body, so tensile and compressive stress will be, respectively, derived in soft rock and coal body. The derived stresses change the stress of the two geologic bodies near contact area from uniaxial states to three-dimensional states which result in strength decreasing and enhancing soft rock and coal body, respectively.

4.3. Effect of Confining Pressure on the Strengths of Two Geologic Bodies. Figure 9 shows the changes of strength with confining pressure when $\alpha=2.5$ and $\sigma_{2}=\sigma_{3}$. 


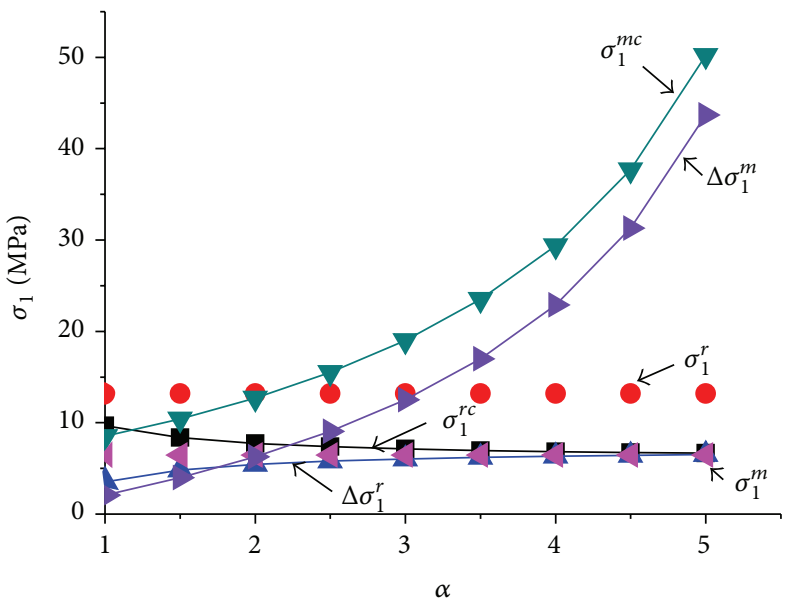

(a) Triaxial compression

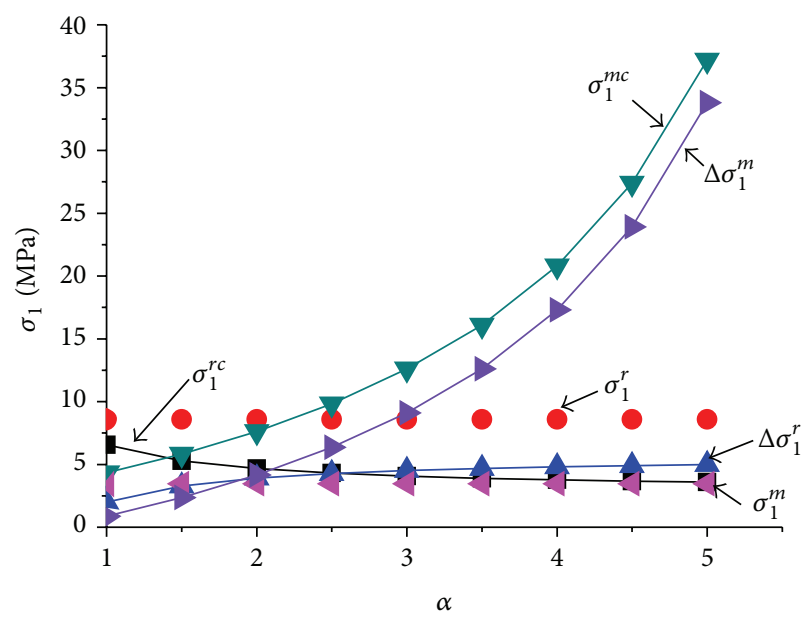

(b) Uniaxial compression

FIGURE 8: Effect of rock stiffness on the strength of coal and rock, respectively, near contact interface.

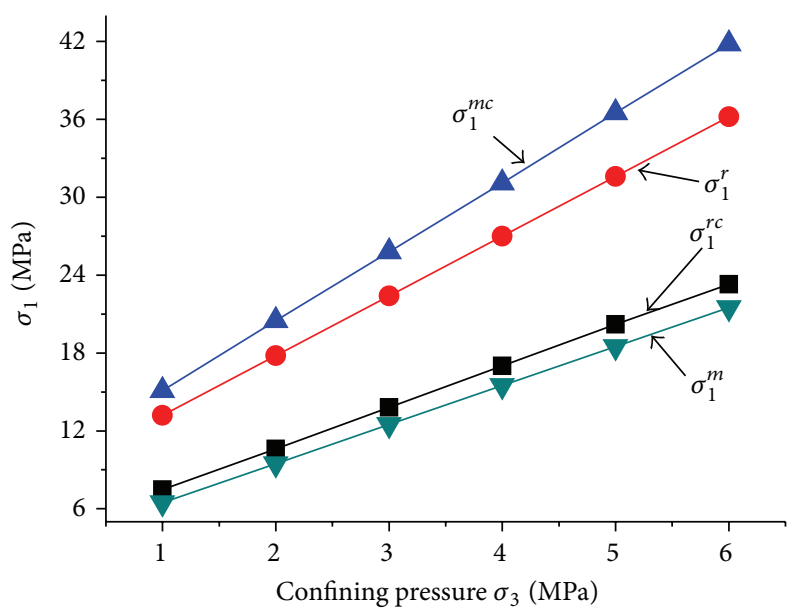

FIGURE 9: Effect of confining pressure on rock and coal body near contact interface.

The strengths of the two geologic bodies are all enhanced with the increasing of confining pressure, and it is seen to be even greater in coal body. The strength of soft rock in this area is significantly lower than the original strength $\sigma_{1}^{r}$. Strength under equal confining pressure is higher than that under unequal confining pressure from the results comparison of Figures 8(a) and 9.

4.4. Effect of Inclined Angle of Interface on the Strengths of Two Geologic Bodies. Changes of principal stresses of the two geologic bodies near the contact area under the action of original stress $\sigma_{1}, \sigma_{2}, \sigma_{3}$ with inclined angle can be determined by employing (11) and (13). The following parameters are set: $c_{m}=1 \mathrm{MPa}, \varphi_{m}=30^{\circ}, E_{m}=1 \mathrm{GPa}$, $c_{r}=2 \mathrm{MPa}, \varphi_{r}=40^{\circ}, \sigma_{1}=5 \mathrm{MPa}$, and $\sigma_{2}=\sigma_{3}=2 \mathrm{MPa}$.

Changes of principal stresses in the two geologic bodies near contact area with inclined angle are illustrated in Figure $10(\alpha=2.5)$, where dotted lines represent the original stresses. As shown in Figure 10(a), $\sigma_{1}$ in soft rock remains unchanged, while $\sigma_{2}$ and $\sigma_{3}$ are slightly increased but do not change significantly with the inclined angle when $\theta \leq 30^{\circ}$. However, $\sigma_{1}$ is rapidly increased, while $\sigma_{2}$ increases first and then decreases with inclined angle and finally approaches the original stress when $\theta>30^{\circ}$. According to M-C yielding criterion, rock strength is weakened in this region which is especially obvious when $\theta>30^{\circ}$. However, changes of principal stresses in coal body show quite different trend as shown in Figure $10(\mathrm{~b})$. When $\theta \leq 30^{\circ}, \sigma_{1}$ remains unchanged, while $\sigma_{3}$ decreases with inclined angle. In this angle scope, coal strength is enhanced when $0 \leq \theta \leq 20^{\circ}$, while it is decreased when $20^{\circ} \leq \theta \leq 30^{\circ}$. When $\theta \geq 50^{\circ}, \sigma_{3}$ and $\sigma_{1}$, respectively, show obvious increasing and decreasing trend, so coal strength is enhanced.

\section{Conclusions}

According to the structure effect on the stability of surrounding rock in soft rock strata, we proposed a microelement model with varying parameters and contact interface. Then, the stress states and strength behavior of two different 


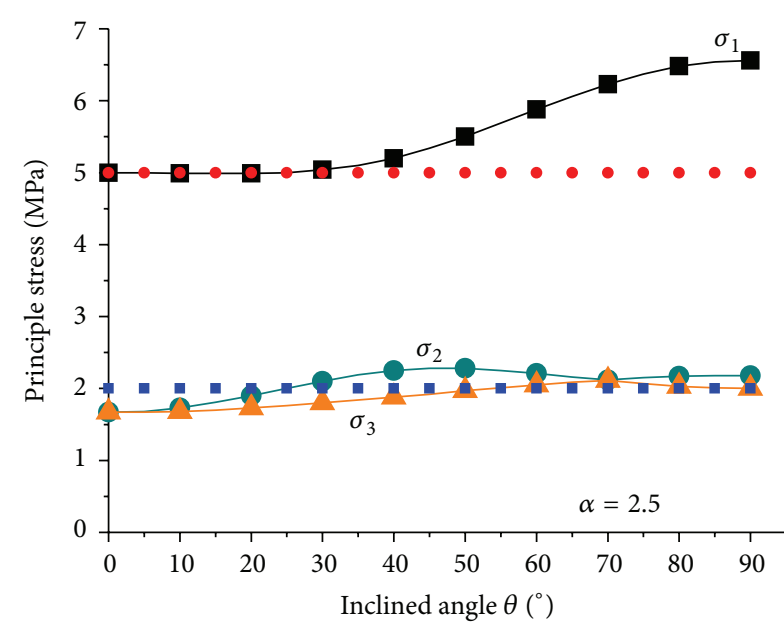

(a) Principal stresses of soft rock

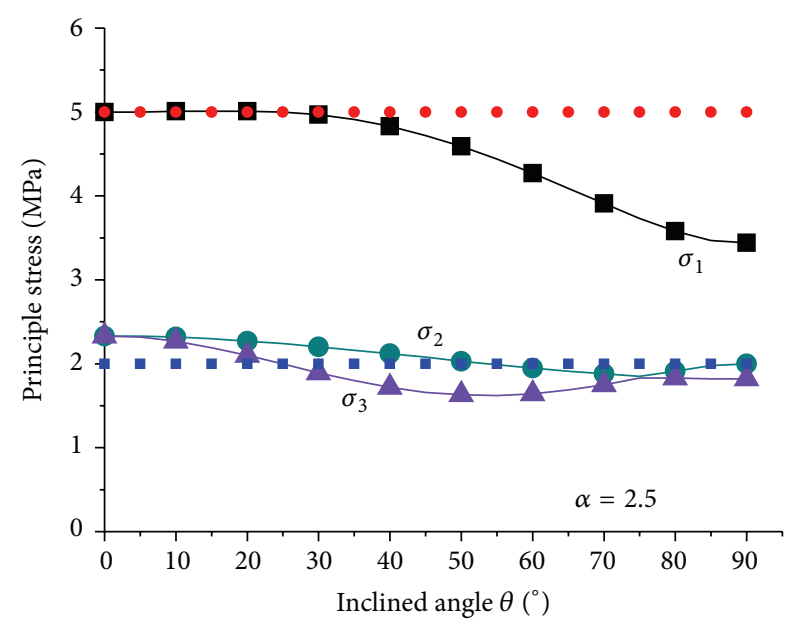

(b) Principal stresses of coal body

FIGURE 10: Effect of inclined angle on principal stresses of rock and coal near contact interface.

geologic bodies were analyzed. Some conclusions are drawn as follows.

(1) The lithological differences between different geologic bodies and the interface effect can change the stress state of the combined model near the contact area which will explicitly affect the strength. Effect of stiffness ratio $\alpha$ on the strength is evidently distinct under different inclined angles, and this means the stiffness effect shows obvious anisotropic characteristic. Stress states of combined model near the contact area are closely related to the stiffness ratio and inclined angle.

(2) Results obtained in this study are not only applied to coal-rock combination model, but are also suitable for the combined model composed of different geologic bodies. For example, the typical combined structure of hard rock-soft rock-hard rock is very common in underground engineering. If the soft rock lies between hard rock, its strength will be enhanced due to the transverse constraint of above and below hard rock which is conducive to the stability of composite structure. However, it is unstable if soft rock is located on one side.

(3) The conclusions of the study are applicable on fully bonded condition for the interface. Yet general bonded condition still exists in the case of engineering structure. For instance, the weak filling medium lies between different rock masses, or different geologic bodies overlap together directly. On these conditions, the interface show both interface effect and friction sliding effect which should be further studied.

\section{Conflict of Interests}

The authors declare that there is no conflict of interests regarding the publication of this paper.

\section{Acknowledgments}

This project is supported by the National Natural Science Foundation of China (Grant no. 51174128) and the Specialized Research Fund for the Doctoral Program of Higher Education of China (Grant no. 20123718110007).

\section{References}

[1] J. C. Jaeger, "Shear failure of anisotropic rocks," Geological Magazine, vol. 97, no. 1, pp. 65-72, 1960.

[2] F. Patton, "Multiple modes of shear failure in rock," in Proceedings of the 1st Congress of International Society of Rock Mechanics, pp. 509-513, 1966.

[3] B. Ladanyi and G. Archambault, "Simulation of the shear behavior of a jointed rock mass," in Proceedings of the 11th Symposium on Rock Mechanics, pp. 105-125, 1970.

[4] N. Barton and V. Choubey, "The shear strength of rock joints in theory and practice," Rock Mechanics Felsmechanik Mécanique des Roches, vol. 10, no. 1-2, pp. 1-54, 1977.

[5] G. Grasselli and P. Egger, "Constitutive law for the shear strength of rock joints based on three-dimensional surface parameters," International Journal of Rock Mechanics and Mining Sciences, vol. 40, no. 1, pp. 25-40, 2003.

[6] G. Grasselli, J. Wirth, and P. Egger, "Quantitative three-dimensional description of a rough surface and parameter evolution with shearing," International Journal of Rock Mechanics and Mining Sciences, vol. 39, no. 6, pp. 789-800, 2002.

[7] Z. Tang, C. Xia, Y. Song, and T. Liu, "Discussion about Grasselli's peak shear strength criterion for rock joints," Chinese Journal of Rock Mechanics and Engineering, vol. 31, no. 2, pp. 356-364, 2012.

[8] B. Amadei and S. Saeb, "Constitutive models of rock joints," in Proceedings of the International Symposium on Rock Joints, pp. 581-594, 1990.

[9] J. P. Seidel and C. M. Haberfield, "A theoretical model for rock joints subjected to constant normal stiffness direct shear," International Journal of Rock Mechanics and Mining Sciences, vol. 39, no. 5, pp. 539-553, 2002. 
[10] M. E. Plesha, "Constitutive models for rock discontinuities with dilatancy and surface degradation," International Journal for Numerical \& Analytical Methods in Geomechanics, vol. 11, no. 4, pp. 345-362, 1987.

[11] C. Yi, L. Zhang, Z.-H. Chen, and H.-P. Xie, "Experimental study on bi-material and bi-body models under compression loading," Rock and Soil Mechanics, vol. 27, no. 4, pp. 571-576, 2006.

[12] J. P. Seidel and C. M. Haberfield, "Laboratory testing of concrete-rock joints in constant normal stiffness direct shear," Geotechnical Testing Journal, vol. 25, no. 4, pp. 1-14, 2002.

[13] Z. D. Zhu, F. D. Xing, W. P. Qu, and W. Z. Chen, "Fractal description of shear strength of cementation plane between rock and concrete," Chinese Journal of Rock Mechanics and Engineering, vol. 25, no. 1, pp. 2910-2917, 2006.

[14] I. W. Johnston and T. S. K. Lam, "Shear behavior of regular triangular concrete/rock joints. Analysis," Journal of Geotechnical Engineering, vol. 115, no. 5, pp. 711-727, 1989.

[15] C. Yi, L. Zhang, Z. Chen, and H. Xie, "A novel description of roughness surface with a modified fractal index Rd," Journal of China University of Mining and Technology, vol. 36, no. 1, pp. 75-80, 2007.

[16] H. P. Xie, Z. H. Chen, H. W. Zhou, C. Yi, and Z.-J. Chen, "Study on two-body mechanical model based on interaction between structural body and geo-body," Chinese Journal of Rock Mechanics and Engineering, vol. 29, no. 9, pp. 1457-1464, 2005.

[17] J. M. Chandra Kishen and K. D. Singh, "Stress intensity factors based fracture criteria for kinking and branching of interface crack: application to dams," Engineering Fracture Mechanics, vol. 68 , no. 2, pp. 201-219, 2001.

[18] C. Zhonghui, F. Jingjing, L. Li, and X. Heping, "Fracture analysis on the interface crack of concrete gravity dam," Key Engineering Materials, vol. 324-325, pp. 267-270, 2006.

[19] I. M. Petukhov and A. M. Linkov, "The theory of post-failure deformations and the problem of stability in rock mechanics," International Journal of Rock Mechanics and Mining Sciences and, vol. 16, no. 5, pp. 57-76, 1979.

[20] D.-M. Guo, R.-S. Yang, T. Zhang, and Y.-H. Zhang, "Evolution mechanism of mesoscopic and macroscopic damage for coalrock combined body under uniaxial compression," in Proceedings of the 4th Academic Symposium about the Deep Rock Mass Mechanics and Engineering Disasters Controlling, pp. 265-269, Beijing, China, 2009.

[21] D.-M. Guo, J.-P. Zuo, Y. Zhang, and R.-S. Yang, "Research on strength and failure mechanism of deep coal-rock combination bodies of different inclined angles," Rock and Soil Mechanics, vol. 32, no. 5, pp. 1333-1339, 2011.

[22] Y. Jiang, T. Wang, Y. Song, X. Wang, and W. Zhang, "Experimental study on the stick-slip process of coal-rock composite samples," Journal of the China Coal Society, vol. 38, no. 2, pp. 177-182, 2013.

[23] Z. Zhang, J. Liu, L. Wang, H. Yang, and J. Zuo, "Effects of combination mode on mechanical properties and failure characteristics of the coal-rock combinations," Journal of the China Coal Society, vol. 37, no. 10, pp. 1677-1681, 2012.

[24] J. Zuo, H. Xie, B. Meng, and J. Liu, "Experimental research on loading-unloading behavior of coal-rock combination bodies at different stress levels," Rock and Soil Mechanics, vol. 32, no. 5, pp. 1287-1296, 2011.
[25] W.-M. Wang, Z.-H. Zhao, and L. Wang, "Elastic-plastic damage analysis for weakly consolidated surrounding rock regarding stiffness and strength cracking," Journal of Mining \& Safety Engineering, vol. 30, no. 5, pp. 679-685, 2013. 


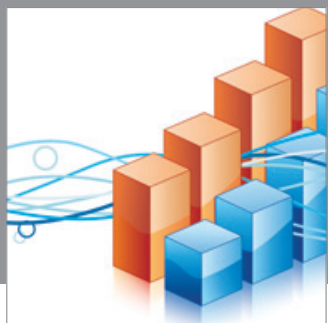

Advances in

Operations Research

mansans

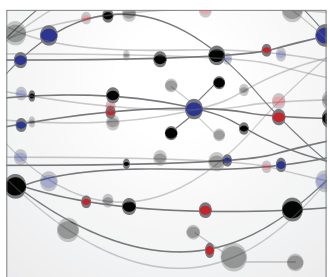

The Scientific World Journal
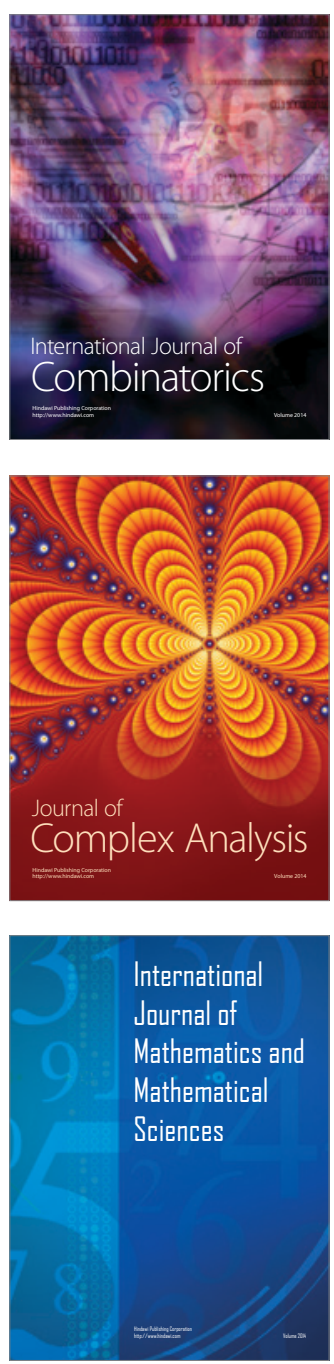
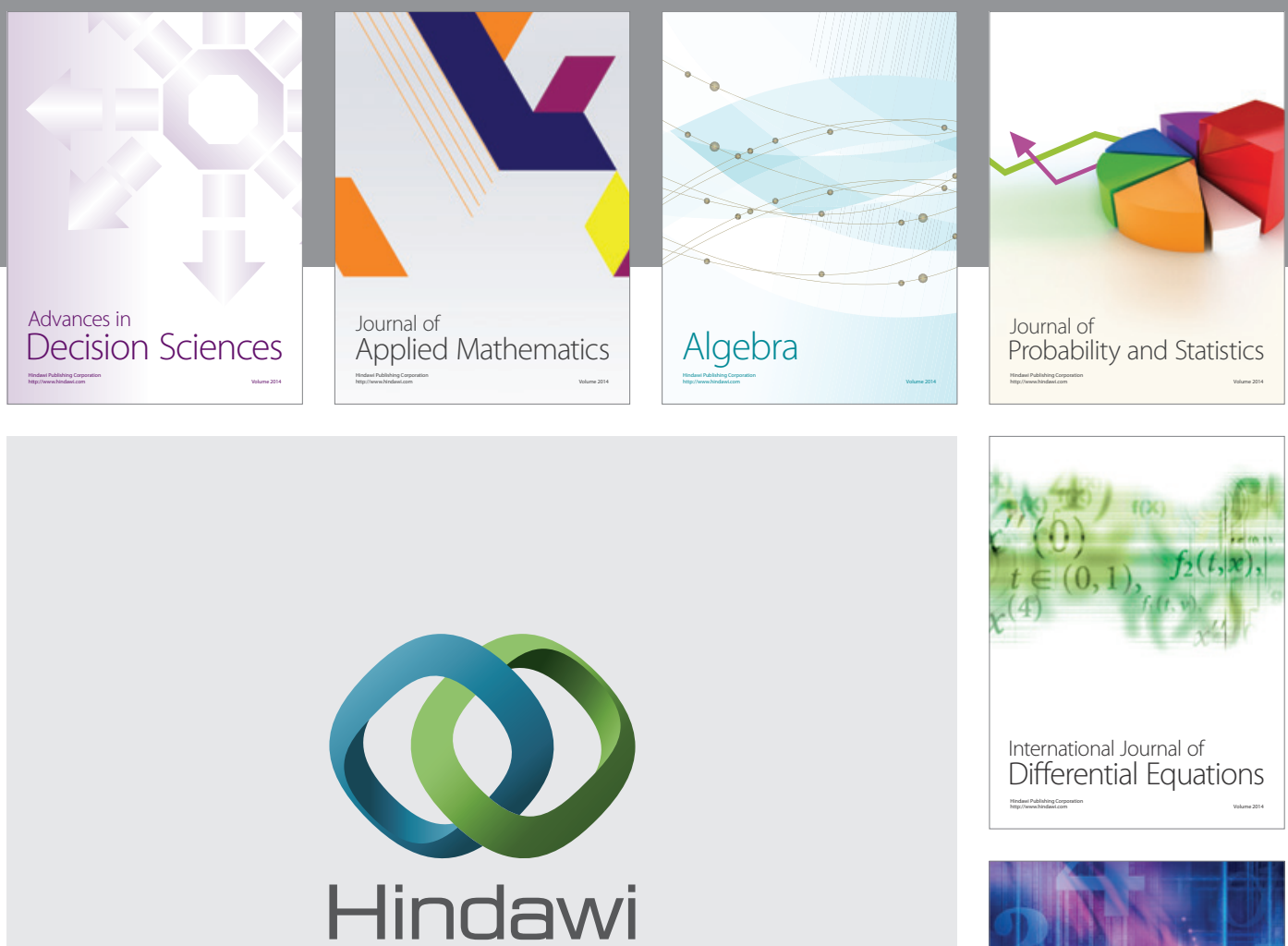

Submit your manuscripts at http://www.hindawi.com
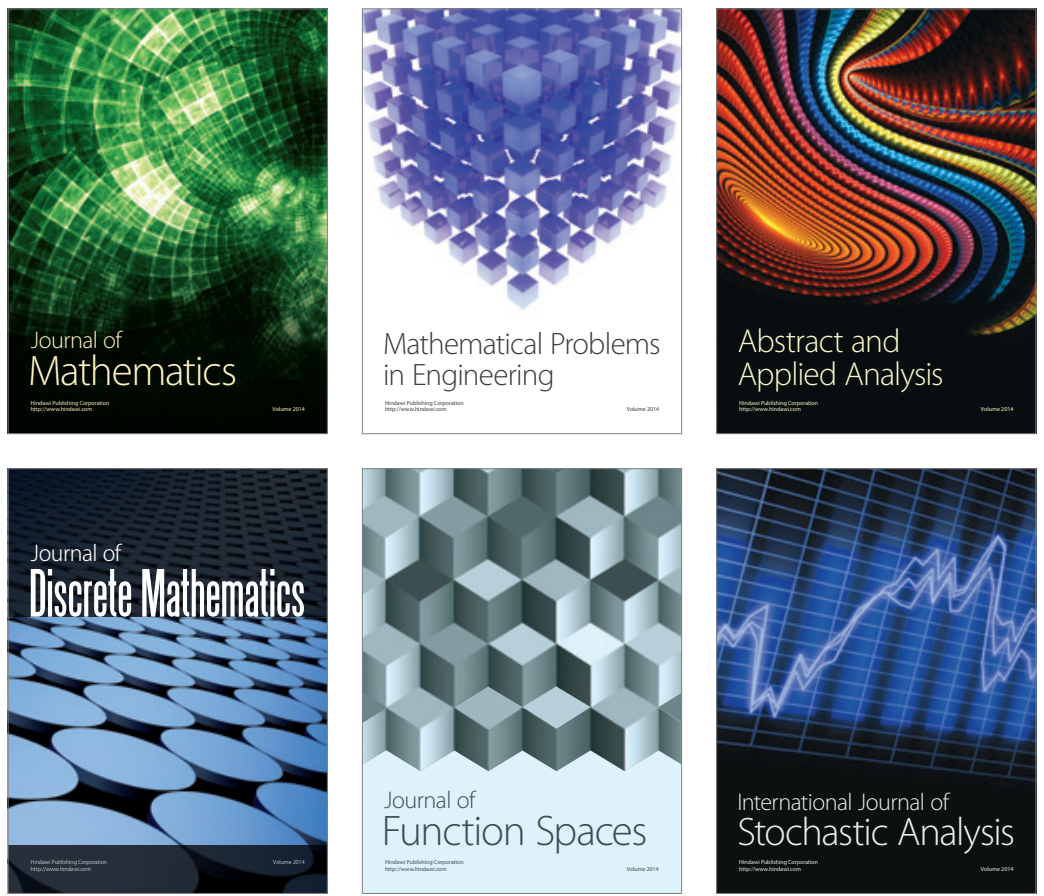

Journal of

Function Spaces

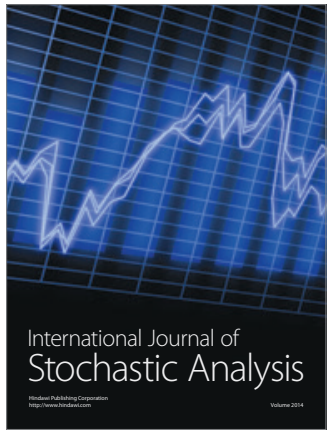

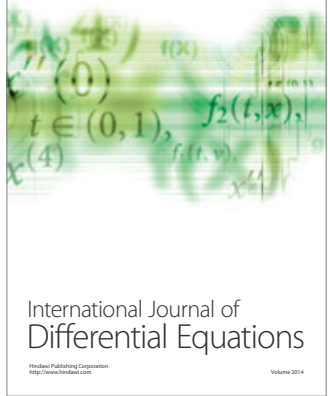
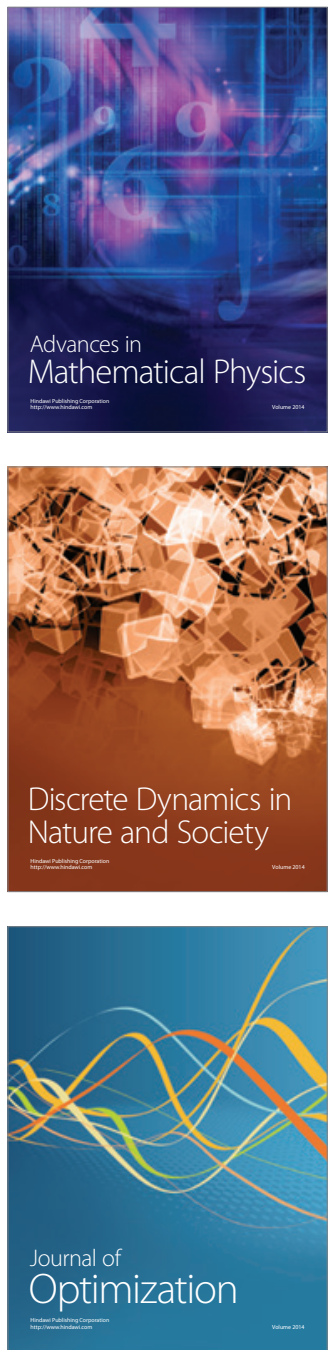